Please do not remove this page

RMIT

UNIVERSITY

\title{
Mechanically tunable high refractive-index contrast TiO2-PDMS gratings
}

Gutruf, Philipp Jonas; Zeller, Eike; Walia, Sumeet; Sriram, Sharath; Bhaskaran, Madhu

https://researchrepository.rmit.edu.au/esploro/outputs/9921862657701341/filesAndLinks?institution=61 RMIT_INST\&index=null

Gutruf, P. J., Zeller, E., Walia, S., Sriram, S., \& Bhaskaran, M. (2015). Mechanically tunable high refractive-index contrast TiO2-PDMS gratings. Advanced Optical Materials, 3, 1565-1569.

https://doi.org/10.1002/adom.201500346

Document Version: Accepted Manuscript

Published Version: https://doi.org/10.1002/adom.201500346

Repository homepage: https://researchrepository.rmit.edu.au

(c) 2015 WILEY-VCH Verlag GmbH \& Co. KGaA, Weinheim

Downloaded On 2023/04/26 17:07:08 +1000

Please do not remove this page 
Thank you for downloading this document from the RMIT Research Repository.

The RMIT Research Repository is an open access database showcasing the research outputs of RMIT University researchers.

RMIT Research Repository: http://researchbank.rmit.edu.au/

\section{Citation:}

Gutruf, P, Zeller, E, Walia, S, Sriram, S and Bhaskaran, M 2015, 'Mechanically tunable high refractive-index contrast TiO2-PDMS gratings', Advanced Optical Materials, vol. 3, pp. 1565-1569.

See this record in the RMIT Research Repository at:

https://researchbank.rmit.edu.au/view/rmit:34205

Version: Accepted Manuscript

Copyright Statement:

(C) 2015 WILEY-VCH Verlag GmbH \& Co. KGaA, Weinheim

Link to Published Version:

https://dx.doi.org/10.1002/adom.201500346 
DOI: 10.1002/adom.((please add manuscript number))

Submitted to

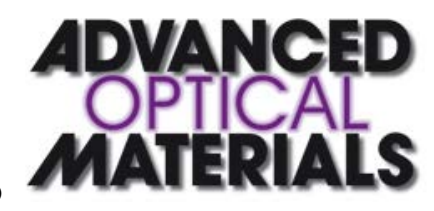

\section{Article type: Communication}

\section{Mechanically Tunable High Refractive Index Contrast $\mathrm{TiO}_{2}-\mathrm{PDMS}_{\text {Gratings }}$}

By Philipp Gutruf,* Eike Zeller, Sumeet Walia, Sharath Sriram, and Madhu Bhaskaran*

Philipp Gutruf, Dr. Eike Zeller, Dr. Sumeet Walia, Dr. Sharath Sriram, and Dr.

Madhu Bhaskaran

Functional Materials and Microsystems Research Group, RMIT University, Melbourne, Victoria (Australia) \& Micro Nano Research Facility, RMIT University, Melbourne, Victoria (Australia)

E-mail: philippgutruf@googlemail.com,madhu.bhaskaran@rmit.edu.au

The rapid progression of stretchable electronics, in particular the integration of a variety of materials onto stretchable substrates, ${ }^{[1,2]}$ has resulted in the emergence of several functional devices such as stretchable and foldable circuits, as well as transparent and epidermal electronics. ${ }^{[3-5]}$ The usage of stretchable and flexible materials is also well established in optics where they are extensively used to create mechanically tunable devices such as tunable lenses, ${ }^{[6]}$ stretchable optical waveguides, ${ }^{[7]}$ and electronic oculus. ${ }^{[8]}$

One of the most prevalent uses of elastomeric materials in tunable optical devices are gratings, which act as tunable diffractive elements. Diffraction gratings are used in a range of applications such as tunable distributed feedback lasers (DFB lasers), ${ }^{[9,10]}$ monochromators, spectrometers, and strain sensors. ${ }^{[11-14]}$ The fabrication of these diffraction gratings relies on micro-imprinting, ${ }^{[15]}$ which requires high aspect ratio structures due to the low refractive index contrast between air (refractive index of 1.0) and the elastomer (generally in the range of $1.3-1.7^{[16,17]}$ for visible light), and is also limited in resolution. Another method reported to achieve mechanically tunable gratings is by wrinkling metal thin films on elastomeric substrates, ${ }^{[18]}$ which only allows sinusoidal gratings. 
Submitted to

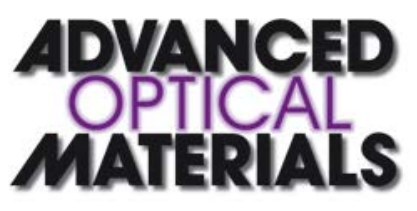

In this work, we propose to introduce oxide thin films, patterned as dot gratings, into an elastomeric material, namely polydimethylsiloxane (PDMS). ${ }^{[14,15]}$ By incorporating titanium dioxide $\left(\mathrm{TiO}_{2}\right)$ as the grating material, we exploit the high refractive index contrast between $\mathrm{TiO}_{2}(\sim 2.7)^{[19]}$ and PDMS ( 1.4), ${ }^{[20]}$ which allows for the grating to have a compact footprint $\left(125 \mu^{2}\right)$ and low film thickness $(100 \mathrm{~nm})$. We demonstrate the functionality as tunable grating structures at two wavelengths with operation at strain levels of up to $15 \%$. Furthermore, we focus on the nano mechanics in strained $\mathrm{TiO}_{2}$ diffractive elements backed by finite element modeling, in situ strained secondary electron imaging and analytical results. In order to experimentally show the functionality of such a proposed grating, we fabricated $\mathrm{TiO}_{2}$ gratings using the transfer technique presented in Gutruf et al. ${ }^{[21]}$ This transfer technique enables the incorporation of oxides in elastomeric substrates by utilizing the weak adhesion of platinum to silicon. For our experiments we chose a small grating period of $1 \mu \mathrm{m}$ which allows for detection of nanometer changes within the grating and is greater than the laser wavelength to stay within the diffraction mode of the grating. ${ }^{[22]}$ Figure 1 shows a step-wise schematic of the fabrication process used to create the dot gratings (a detailed description of the synthesis can be found in the Methods section). Special precaution needs to be taken to conduct the step shown in Figure 1d. Here, a compressive stress is introduced by curing the PDMS at an elevated temperature $\left(120^{\circ} \mathrm{C}\right)$. This stress results in a negative strain of $\sim 4 \%$ while peeling the structure off the host substrate. The fabricated grating period reduces by $4 \%$ as a direct result of this effect. As such, the chosen $1.00 \mu \mathrm{m}$ grating period shrinks to a $0.96 \mu \mathrm{m}$ period when released from the rigid carrier. 


\section{Submitted to

In order to test the performance of the fabricated diffraction grating, it was placed in a uniaxial stretching stage and studied under two laser wavelengths (543.5 and $668.3 \mathrm{~nm}$ ). A schematic is presented in Figure 2, with full details presented in the Methods section.

Once the laser transmits through the grating, a diffraction pattern can be observed on a screen placed behind the grating. The locations of the first order diffraction spots of the laser were measured for compressive (negative) and tensile (positive) applied strains ranging from $-4 \%$ to $18 \%$. Photographs of the diffraction images obtained as a function of strain for the green laser illumination are presented in Figure 3a. The diffraction image under red laser illumination is displayed in the Supporting Information (see Figure S1). Figure 3a shows a successive evolution of the diffraction pattern under increasing strain (-4\% to $18 \%)$. It can be observed that the first order diffraction maxima in the $\mathrm{X}$-direction moves towards zero order (aimed at the center of the calibrated semi-transparent screen) with an increase in applied strain. Furthermore, it can be observed that the diffraction spots in the Y-direction move away from the zero order as predicted. A second order diffraction pattern can also be observed, which is a superposition of the first order diffraction in $\mathrm{X}$ and $\mathrm{Y}$ direction. It can also be observed that the first order diffraction continues to exhibit a sharp pattern even under strain indicating that the grating elements retain their shape. Furthermore, an expected drop in diffraction intensity is observed under higher strains due to an increased duty cycle of the grating period under strain. Based on the positions of the diffracted maxima, the diffraction angle $\theta$ was calculated using the basic trigonometric relationship of the spacing of the first order diffraction spot from the center (a) to the distance of the grating from the screen (d). This is further elaborated on in the Methods section.

Figure $3 \mathrm{~b}$ shows the first order diffraction angle $\theta$ for the $\mathrm{X}$ and $\mathrm{Y}$ directions. It can be seen that depending on the laser wavelength and applied strain, a change in diffraction angle is 
Submitted to

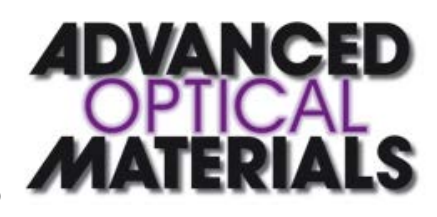

induced. The diffraction angle $\theta$ in the $\mathrm{X}$ direction decreases due to an increase in grating period. Conversely, $\theta$ increases in the $\mathrm{Y}$ direction due to the reduction in grating period. The result is consistent for both utilized wavelengths (543.5 and $668.3 \mathrm{~nm}$ ). While considering the applied strain and the Poisson's ratio of PDMS, the effective change in the grating period can be analytically evaluated (detailed in the Methods section). This change in the grating period can be expressed as the corresponding first order diffraction angle $\theta$ is also presented in Figure 3 (the curves labelled 'Analytical'). The experimental and analytical results show excellent agreement, especially under tensile strain. During compression, the PDMS substrate can experience bowing, which is not accounted for by the analytical estimations, resulting in a slight deviation from experimental results.

The close agreement of the experimental and analytical results (Figure 3), combined with the observation of the first order diffraction retaining its shape, suggests that the $\mathrm{TiO}_{2}$ nanostructures are not deforming under strain, which indicates that for the purposes of redistributing strain, the elastomeric material amidst the features may be subjected to an extensive strain along the $\mathrm{X}$ direction, with modest compression along the $\mathrm{Y}$ direction. In order to test this hypothesis and evaluate the deformation characteristics of the high Young's modulus $\mathrm{TiO}_{2}$ features embedded in the low Young's modulus PDMS, we undertook threedimensional (3D) finite element modeling (FEM). To minimize computational requirements and ensure aspect ratios suitable for FEM, we simplify the device by reducing the number of diffractive elements (to a $6 \times 6$ array) as well as limiting the thickness and size of the elastomeric material (as shown in Figure 4a).

To simulate the effect of strain, the substrate was displaced by $4 \mu \mathrm{m}$ in the $\mathrm{X}$ direction, equivalent to an applied uniaxial strain of $20 \%$. The resulting total deformation across the model can be seen from the 3D map presented in Figure 4b. It can be observed that the overall 
Submitted to

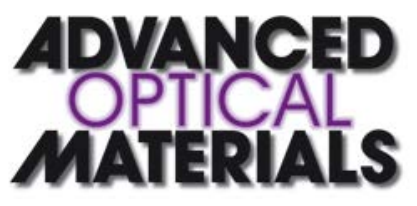

total deformation of the PDMS substrate is uniform, with no distortion introduced by the $\mathrm{TiO}_{2}$ grating. To gain insight into the strain occurring within the grating, we carried out a normalized strain analysis, displayed in Figure 4c. It can be seen that the $\mathrm{TiO}_{2}$ discs do not deform owing to their high Young's modulus, while the low modulus PDMS is seen to deform freely around the nanostructures. The PDMS amongst the $\mathrm{TiO}_{2}$ discs compensates for the overall deformation in the direction of the applied strain.

As a result, the simulation clearly indicates that when hard $\mathrm{TiO}_{2}$ discs are introduced into PDMS, they can move uniformly along with the elastomeric substrate, without undergoing deformation or buckling.

In order to verify this theoretical observation, we carried out in situ surface characterisation using a custom made stretching stage under an SEM (details can be found in the experimental section). The grating (as shown in Figure 4d) which was previously used for diffraction measurements over multiple cycles ( $\sim 30$ cycles), is subjected to a strain of $15 \%$. This value of strain is chosen to be well beyond the usual threshold for the formation of micro-cracking of well adhered thin films on elastomeric substrates ${ }^{[23]}$. As seen in Figure 4d, the change in period can be observed when compared to the unstrained device seen in Figure 1g, as well as no micro cracking or deformation of the oxide features, therefore we can conclude that the strain acting on the $\mathrm{TiO}_{2}$ diffractive elements is negligible, therefore we expect the stretchable grating to retain its performance over many cycles ( 30) without alteration of optical performance.

As such, the FEM simulation results have been verified through in situ SEM observations to be a valid and accurate model for the investigation of embedded oxide films in an elastomeric matrix. Eventually, by monitoring the movement of these $\mathrm{TiO}_{2}$ features, an accurate representation of the local strain can be obtained. Furthermore, the grating is almost 
Submitted to

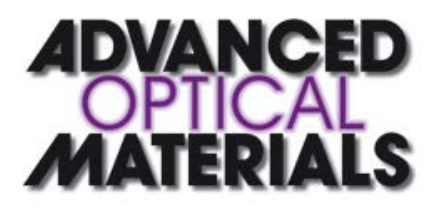

'mechanically invisible', as it does not impact the substrate deformation, being analogous to a blank PDMS substrate (see Supporting Information Figure S2).

In order to gain further insight into the strain occurring in the grating, the measured first order diffraction angle was used to determine the effective grating period using the grating equation (discussed in the Methods section). By calculating the change in grating period, the strain in the grating can be determined. To compare with the experimental results obtained for the two wavelengths, analytical calculations (analogous to those presented in Figure 3) and results from the FEM for displacement of the $\mathrm{TiO}_{2}$ nanostructures were also considered. This comparison is presented in Figure 5.

Figure 5 shows that the measured and applied strains are closely matched and follow the analytical and FEM predictions. It also can be seen that the analytical result closely matches the simulation for lower strains, while there is a slight deviation at higher strains. Over the applied strain range from $-4 \%$ to $18 \%$, the measured strain is linearly increasing in the $\mathrm{X}$ direction from $-4.0 \%$ to $19.7 \%$ for green laser light $(543.5 \mathrm{~nm})$ and from $-6.8 \%$ to $16.75 \%$ for the red laser light $(668.3 \mathrm{~nm})$. In the $\mathrm{Y}$ direction, the period decreases from $1 \%$ to $-6 \%$ for both green and red laser wavelengths.

It is evident that the experimental results are in agreement with the simulations. Only slight variation is observed under compression, which is due to the bowing of the PDMS substrate. As the measured strain can be correlated to the applied strain, the as-designed gratings provide an accurate illustration of the local strain probed by the oxide gratings. The slight deviation from the simulated results in the $\mathrm{Y}$ direction at higher strains can be attributed to measurement errors in the mechanical setup and the thermal expansion through the laser beam. $^{[24]}$ 
Submitted to

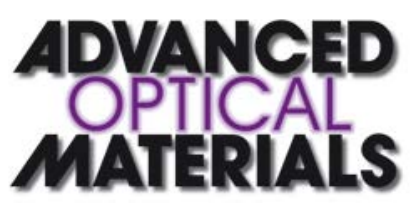

Due to the very short grating period of only $960 \mathrm{~nm}$, the measurable change in periodicity correlates to the variation in the diffraction angle, which is dependent on the illumination wavelength. Considering a measurable resolution of $0.1^{\circ}$ for the diffraction angle under green laser illumination, the smallest measurable change in period length ranges from 2.2-3.7 nm in the $\mathrm{X}$ direction and 2.1-2.5 nmin the Y-direction. For the red light, the smallest measurable change in grating period ranges from $1.4 \mathrm{~nm}$ to $2.6 \mathrm{~nm}$ in $\mathrm{X}$ direction and $1.4 \mathrm{~nm}$ to $1.8 \mathrm{~nm}$ in Y direction. It should also be noted that the change of sensitivity with strain is caused by a nonlinear relation between the measured diffraction angle and the change in diffraction period. This correlates to a slight variation in theoretical sensitivity. As a result, it is expected that a longer wavelength results in a higher sensitivity due to a larger diffraction angle.

When compared to polymer-only gratings, the device presented in this study provides distinct advantages. It has a compact footprint $\left(125 \mu^{2}\right)$ and the ability to operate in transmission, unlike widely reported reflection gratings, ${ }^{[25]}$ which eliminates the need for a complex optical setup. Furthermore, as the oxide features are not deformed even on straining the elastomeric host, the deformation of the grating features do not have to be taken into account, which offers a distinct advantage over gratings fabricated by soft lithography. ${ }^{[26]}$

The embedded oxide features in our gratings result in a completely flat device surface. This allows possible integration in ultra-flat stretchable devices or flexible devices with a plastic substrate. This represents a distinct advantage over gratings that are fabricated by buckling of hard films on elastomeric substrates. ${ }^{[27-29]}$

In conclusion we show in this article, we demonstrate $\mathrm{TiO}_{2}$ dot gratings with mechanically tunable characteristics. This was achieved by exploiting the high refractive index contrast of $\mathrm{TiO}_{2}$ and PDMS combined with a short grating period of $960 \mathrm{~nm}$, which allows for a compact footprint of $125 \mu \mathrm{m}^{2}$. It is shown that the $\mathrm{TiO}_{2}$ grating elements experience almost no strain 
Submitted to



and have minimal impact on the mechanical properties of the flexible platform, while deforming seamlessly when the host elastomer is subjected to an external strain. As such, this study shows that by obtaining the first order diffraction angle, an accurate representation of an applied 2D strain can be created without the use of any sophisticated external optical equipment. Furthermore, an insight into the mechanics of such hard elements in an elastomeric matrix is demonstrated. This can allow for the adoption of this design approach in stretchable electronics as well as mechanically tunable applications in photonics and strain mapping, with potential applications in flat diffractive optics.

\section{Experimental}

Fabrication of Stretchable Gratings. The fabrication of the transparent PDMS-based $\mathrm{TiO}_{2}$ devices relies on the transfer technique described in detail in Gutruf et al. ${ }^{[21]}$ This technique is also schematically presented in Figure 1, in the context of this work. The process starts with a platinum layer deposited by electron beam evaporation on a standard, pre-cleaned silicon wafer (Figure 1a). It should be noted that no titanium layer is utilized between platinum and silicon, as per convention, in this case. A $250 \mathrm{~nm}$ thick polymethylmethacrylate (PMMA) layer was applied to the platinum-coated silicon wafer via spin coating followed by a hard bake at $180^{\circ} \mathrm{C}$. The electron beam sensitive PMMA was subsequently exposed using an electron beam lithography system (Nabity EBL system on a FEI Nova NanoSEM equipped with a field emission gun) by writing the negative mask of the diffraction grating in a serial process. The written structures were $500 \mathrm{~nm}$ diameter openings with a separation of $1 \mu \mathrm{m}$. The grating consists of $120 \times 120$ periods giving it a total dimension of $120 \times 120 \mu^{2}$. A subsequent immersion in a developer was used to wash away the exposed regions of the transmission diffraction grating. The sample was then placed in an electron beam evaporator (Lesker PVD-75) and a $\mathrm{TiO}_{2}$ layer of $100 \mathrm{~nm}$ thickness was deposited (Figure 1b). This $\mathrm{TiO}_{2}$ 
Submitted to

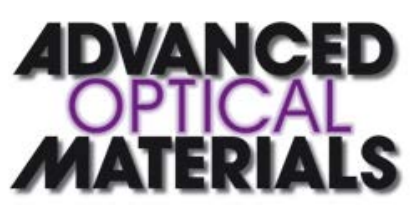

thin film has a refractive index of 2.77 at $543.5 \mathrm{~nm}$ and 2.72 at $668.3 \mathrm{~nm}$ (see Supporting Information Figure S3). Subsequently a lift-off was performed in an acetone bath removing the excess $\mathrm{TiO}_{2}$ (Figure 1c). This was followed by the removal of the $\mathrm{TiO}_{2} / \mathrm{Pt}$ sandwich from its rigid carrier by casting PDMS (2 mm thick, with a mixing ratio of base to curing agent of 10:1) onto the $\mathrm{TiO}_{2}$ layer and a subsequent hot plate cure at $120^{\circ} \mathrm{C}$ for $8 \mathrm{~min}$ and an immediate peel-off (Figure 1d) The wafer-sized $\mathrm{TiO}_{2} / \mathrm{PDMS}$ device was flipped over onto a silicon carrier and the Pt layer removed by reactive ion etching $(7.5 \mathrm{~min}, 100 \mathrm{~W}$, Ar atmosphere, 70 mTorr working pressure) leaving the grating exposed (Figure 1e). The device was then carefully lifted off the carrier (Figure 1f), imaged to verify grating periodicity (Figure 1g), and sectioned into $50 \mathrm{~mm} \times 50 \mathrm{~mm}$ specimen for testing.

In situ Diffraction Angle Measurements under Strain. In order to measure the change of the diffracted beam when the flexible grating is strained a setup as depicted in Figure 2 was utilized. The PDMS block with the embedded grating was mounted in a high precision stretching stage. A Uniphase 1974P He-Ne Laser [at $543.5 \mathrm{~nm}$ wavelength (green)] and Thorlabs LDM670 diode laser [at $668.3 \mathrm{~nm}$ wavelength (red)] were used as coherent light sources. The wavelength was measured using a spectrometer to minimize errors. The laser beam was aligned perpendicular to the grating surface, so that the incident light would propagate through the PDMS block, be diffracted by the grating, and finally illuminates a semi-transparent screen placed at a distance of $10 \mathrm{~cm}$. The zero-order diffraction was aligned to the center of a set of concentric rings on the screen (a 'target'), with $10 \mathrm{~mm}$ spacing between the rings, to allow for precise evaluation of the position of the diffraction spots. Behind the screen, the intensity maxima of the first order diffraction were imaged using a Canon 550D SLR camera. The total length of the clamped PDMS block was measured using a digital caliper. The sample was stretched from $10.2 \mathrm{~mm}$ to $12.6 \mathrm{~mm}$ in $0.1 \mathrm{~mm}$ increments. The distance of intensity maxima in relation to the rings on the target was evaluated with the 
Submitted to

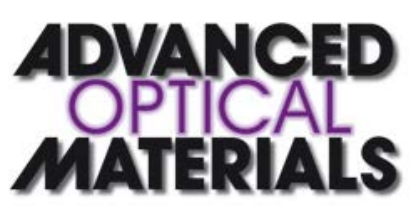

ImageJ image processing software. Photographs of diffraction patterns as a function of strain for both laser wavelengths are presented as Supporting Information (Figure S2). In order to minimize systemic errors (for example, caused by a tilt of the screen), the two maxima in the vertical and horizontal directions were averaged. Having established the locations of the first order diffraction maxima, the diffraction angle $\theta$ could be determined using the trigonometric relation:

$$
\tan \theta=\frac{a}{d}
$$

where, $a$ the spacing between the first order diffraction maxima from the center and $d$ is the distance between the grating and the screen (10 cm in this case). Depending on the diffraction angle, the period $\Lambda$ of the stretched grating was calculated using the grating equation:

$$
\sin \theta=\frac{m \lambda}{\Lambda}
$$

where, $m$ represents the $m^{\text {th }}$ order of diffraction and $\lambda$ the wavelength. The $0 \%$ strain state was established by the determining equality of performance for the $\mathrm{X}$ and $\mathrm{Y}$ distance $\left(a_{\mathrm{X}}=a_{\mathrm{Y}}\right)$ as this was a 2D dot grating with identical $\mathrm{X}$ and $\mathrm{Y}$ periodicity). The sensitivity was determined as a ratio of the difference of two adjacent measurements of grating period to the change in the diffraction angle. The strain displayed in Figure 5 was calculated using the change in period 4 , obtained from Equations 1 and 2, with respect to the initial period length of 0.96 $\mu \mathrm{m}$. This approach was utilized for experimental, analytical, and FEM results.

Analytical Estimation. The ideal performance of the grating was analytically calculated by assuming a seamless movement of the $\mathrm{TiO}_{2}$ features within the PDMS substrate. A change in grating period of $-4 \%$ to $18 \%$ for the $\mathrm{X}$ direction, and a corresponding change in the $\mathrm{Y}$ direction based on the Poisson's ratio of $0.4^{[30]}$ for PDMS were determined. It was assumed that the $\mathrm{TiO}_{2}$ features undergo no deformation. The resulting grating period was used to 
Submitted to

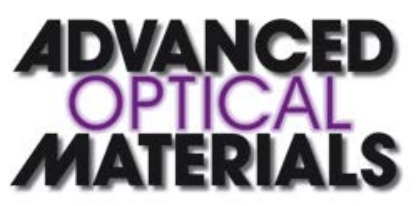

determine the change in the first order diffraction angle using Equation 1 for Figure 2. Based on the first order diffraction angle change, the ideal strain was calculated using Equation 2 for Figure 5. Refractive index changes under strain were negligible even under strains as large as $50 \%$ (Figure S4).

Finite Element Modelling. The finite element modelling (FEM) was carried out using an ANSYS Multiphysics (Version 15) simulation tool. The physical dimensions for the simulated solid were as displayed in Figure 4a. The PDMS slab was $20 \mu \mathrm{m} \times 10 \mu \mathrm{m} \times 2.5 \mu \mathrm{m}$. The materials properties for PDMS were set as follows: Young's modulus of $20 \mathrm{MPa},{ }^{[18]}$ density of $965 \mathrm{~kg} \mathrm{~m}^{-3}$, ${ }^{[31]}$ and Poisson's ratio of $0.4 .^{[30]}$ The $\mathrm{TiO}_{2}$ discs embedded in the PDMS were $500 \mathrm{~nm}$ in diameter and $100 \mathrm{~nm}$ thick, with Young's modulus of $1.4 \times 10^{6} \mathrm{MPa}^{[32]}$ density of $4,260 \mathrm{~kg} \mathrm{~m}^{-3},{ }^{[33]}$ and Poisson's ratio of $0.28 .^{[34]}$ A twodimensional dot grating was defined with a periodicity of $0.96 \mu \mathrm{m}$ and $6 \times 6$ periods.

In situ SEM strain analysis. In situ SEM strain analysis was carried out using a custom made stretching stage capable of applying displacements of $2.5 \mu \mathrm{m}$ steps to elastomeric samples whilst being placed in a Field Emission Inc. Quanta 200 ESEM. The samples were imaged in low vacuum mode at 0.5 Torr pressure using a large area field detector.

\section{Acknowledgements}

PG acknowledges an Australian Government Endeavour International Postgraduate Research Scholarship. The authors acknowledge Professor Arnan Mitchell for helpful discussions and the facilities and technical assistance of the Australian Microscopy and Microanalysis Research Facility at the RMIT Microscopy and Microanalysis Facility.

Received: ((will be filled in by the editorial staff))

Revised: ((will be filled in by the editorial staff)) Published online: ((will be filled in by the editorial staff))

\section{REFERENCES}

[1] P. Gutruf, S. Walia, M. N. Ali, S. Sriram, M. Bhaskaran, Appl. Phys. Lett. 2014, 104, 021908

[2] K. S. Kim, Y. Zhao, H. Jang, S. Y. Lee, J. M. Kim, K. S. Kim, J.-H. Ahn, P. Kim, J.Y. Choi, B. H. Hong, Nature 2009, 457, 706-10 
Submitted to

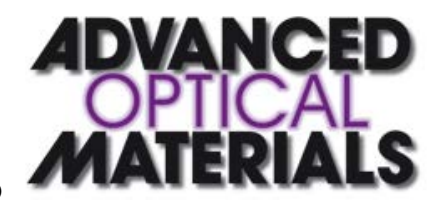

[3] D.-H. Kim, J.-H. Ahn, W. M. Choi, H.-S. Kim, T.-H. Kim, J. Song, Y. Y. Huang, Z.

Liu, C. Lu, J. A. Rogers, Science 2008, 320, 507-11

[4] K. Park, D. K. Lee, B. S. Kim, H. Jeon, N. E. Lee, D. Whang, H. J. Lee, Y. J. Kim, J. H. Ahn, Adv. Funct. Mater. 2010, 20, 3577-82

[5] J. Kim, A. Banks, H. Cheng, Z. Xie, S. Xu, K.-I. Jang, J. W. Lee, Z. Liu, P. Gutruf, X. Huang, P. Wei, F. Liu, K. Li, M. Dalal, R. Ghaffari, X. Feng, Y. Huang, S. Gupta, U. Paik, J. A. Rogers, Small 2015, 11, 906-12

[6] S. W. Lee, S. S. Lee, Appl. Phys. Lett. 2007, 90, 121129

[7] J. Missinne, S. Kalathimekkad, B. Van Hoe, E. Bosman, J. Vanfleteren, G. Van

Steenberge, Opt. Express 2014, 22, 4168-79

[8] H. C. Ko, M. P. Stoykovich, J. Song, V. Malyarchuk, W. M. Choi, C.-J. Yu, J. B. Geddes Iii, J. Xiao, S. Wang, Y. Huang, Nature 2008, 454, 748-53

[9] Z. Li, Z. Zhang, T. Emery, A. Scherer, D. Psaltis, Opt. Express 2006, 14, 696-701

[10] B. Wenger, N. Tétreault, M. E. Welland, R. H. Friend, Appl. Phys. Lett. 2010, 97, 193303

[11] A. D. Kersey, M. A. Davis, H. J. Patrick, M. LeBlanc, K. Koo, C. Askins, M. Putnam, E. J. Friebele, J. Lightwave Technol. 1997, 15, 1442-63

[12] K. Meerholz, B. L. Volodin, Sandalphon, B. Kippelen, N. Peyghambarian, Nature 1994, 371, 497-500

[13] P. Rochon, E. Batalla, A. Natansohn, Appl. Phys. Lett. 1995, 66, 136-8

[14] J. L. Wilbur, R. J. Jackman, G. M. Whitesides, E. L. Cheung, L. K. Lee, M. G. Prentiss, Chem. Mater. 1996, 8, 1380-5

[15] J. A. Rogers, D. Qin, O. J. Schueller, G. M. Whitesides, Rev. Sci. Instrum. 1996, 67, 3310-9

[16] P. R. Cooper, Appl. Opt. 1982, 21, 3413-5

[17] P. Polynkin, A. Polynkin, N. Peyghambarian, M. Mansuripur, Opt. Lett. 2005, 30, 1273-5

[18] N. Bowden, S. Brittain, A. G. Evans, J. W. Hutchinson, G. M. Whitesides, Nature 1998, 393, 146-9

[19] L. Zou, W. Withayachumnankul, C. M. Shah, A. Mitchell, M. Bhaskaran, S. Sriram, C. Fumeaux, Opt. Express 2013, 21, 1344-52

[20] S. Motakef, T. Suratwala, R. Roncome, J. Boulton, G. Teowee, D. Uhlmann, J. NonCryst. Solids 1994, 178, 37-43

[21] P. Gutruf, C. M. Shah, S. Walia, H. Nili, A. S. Zoolfakar, C. Karnutsch, K. Kalantarzadeh, S. Sriram, M. Bhaskaran, NPG Asia Mater. 2013, 5, e62

[22] V. Karagodsky, C. J. Chang-Hasnain, Opt. Express 2012, 20, 10888-95

[23] S. P. Lacour, D. Chan, S. Wagner, T. Li, Z. Suo, Appl. Phys. Lett. 2006, 88, 204103

[24] J. A. Rogers, MRS Bull. 2001, 26, 530-4

[25] T. Ma, H. Liang, G. Chen, B. Poon, H. Jiang, H. Yu, Opt. Express 2013, 21, 11994-

2001

[26] A. N. Simonov, S. Grabarnik, G. Vdovin, Opt. Express 2007, 15, 9784-92

[27] T. Ohzono, K. Suzuki, T. Yamaguchi, N. Fukuda, Adv. Opt. Mater. 2013, 1, 374-80

[28] J. Parra-Barranco, M. Oliva-Ramirez, L. Gonzalez-Garcia, M. Alcaire, M. Macias-

Montero, A. Borras, F. Frutos, A. R. Gonzalez-Elipe, A. Barranco, ACS Appl. Mater.

Interfaces 2014, 6, 11924-31

[29] S. Tawfick, M. De Volder, D. Copic, S. J. Park, C. R. Oliver, E. S. Polsen, M. J.

Roberts, A. J. Hart, Adv. Mater. (Weinheim, Ger.) 2012, 24, 1628-74

[30] Y. Xia, E. Kim, X.-M. Zhao, J. A. Rogers, M. Prentiss, G. M. Whitesides, Science 1996, 273, 347-9 
Submitted to

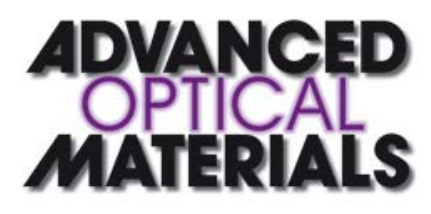

[31] A. Nisar, N. Afzulpurkar, B. Mahaisavariya, A. Tuantranont, BMEI 2008. 2008, 1, 531-5

[32] C. Ottermann, R. Kuschnereit, O. Anderson, P. Hess, K. Bange, MRS Proceedings 1996, 436, 251

[33] M. Reddy, V. V. Rao, B. Reddy, S. N. Sarada, L. Ramesh, Nanosci. Nanotechnol. Lett. 2012, 4, 105-9

[34] M. Mayo, R. Siegel, A. Narayanasamy, W. Nix, J. Mater. Res. 1990, 5, 1073-82 


\section{Submitted to
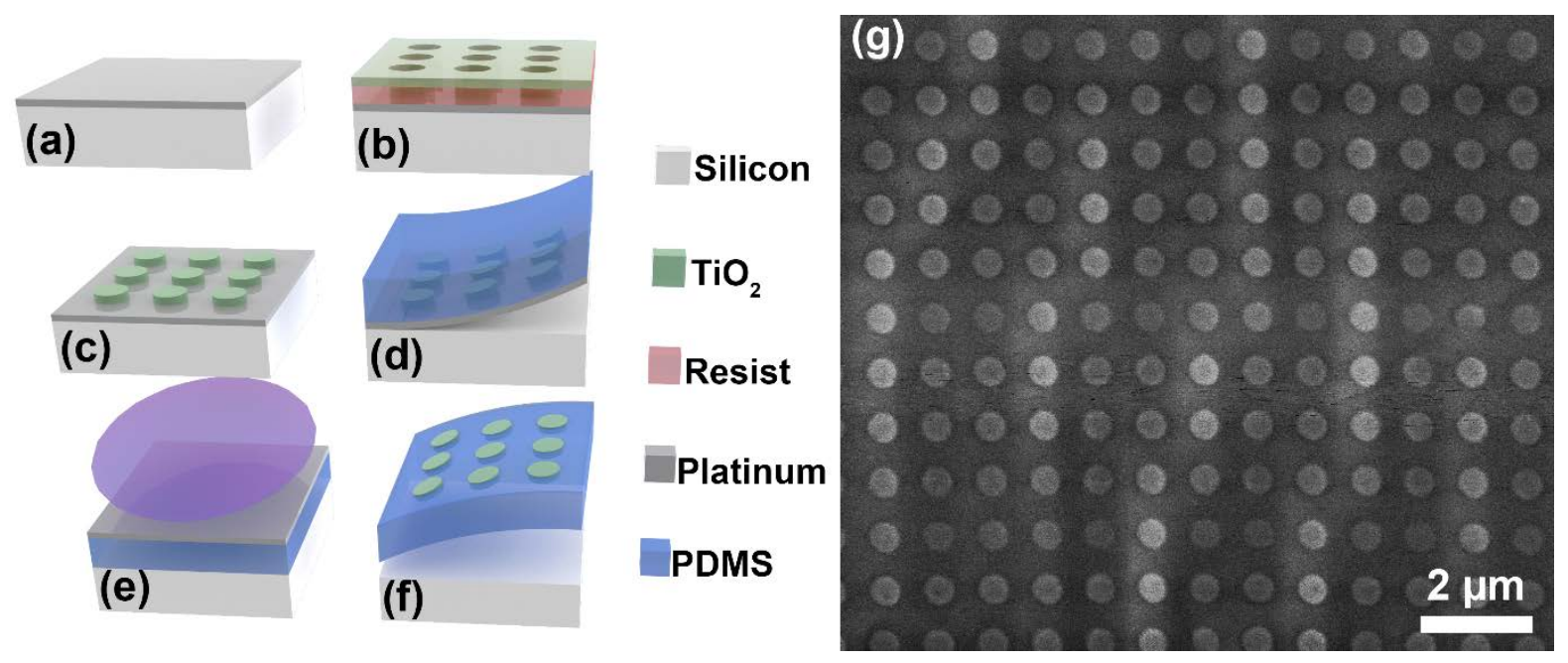

Figure 1. Fabrication of the $\mathrm{TiO}_{2}-\mathrm{PDMS}$ stretchable gratings: (a) Platinum-coated silicon wafer. (b) Definition of features via electron beam lithography and physical vapor deposition of $\mathrm{TiO}_{2}$. (c) Lift-off removal of $\mathrm{TiO}_{2}$ and resist. (d) Spin-coating and curing of PDMS with subsequent peel from carrier substrate. (e) Platinum layer removal through reactive ion etching. (f) Release from carrier substrate. (g) $\mathrm{TiO}_{2}$ gratings embedded in PDMS imaged with low vacuum secondary electron imaging.
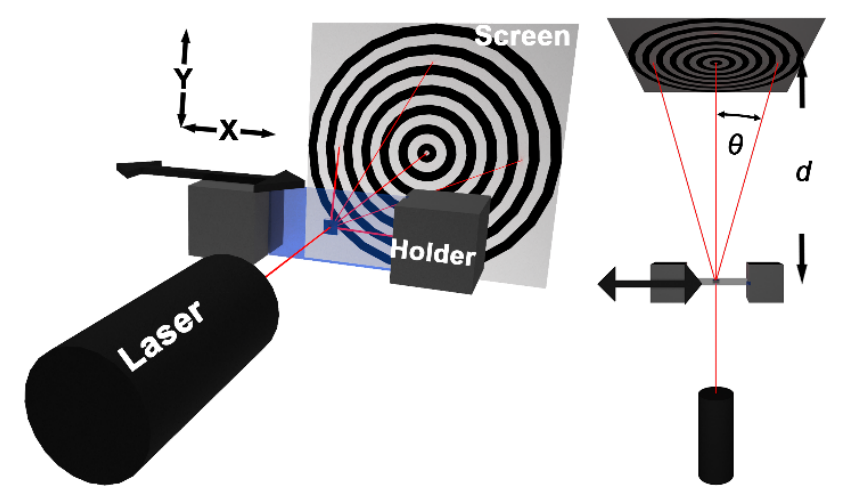

Figure 2. Schematic of the experimental setup in isometric (left) and top (right) view. The laser light source is focused on the stretchable grating affixed to a high resolution stretching apparatus allowing in situ uniaxial strain application. The projected diffraction pattern are visualized on a semi-transparent screen. The first order diffraction angle $\theta$ and the distance from the grating to the projection plane $d$ are indicated. It should be noted that X denotes the horizontal direction parallel to applied strain, and Y the direction normal to the applied strain. 

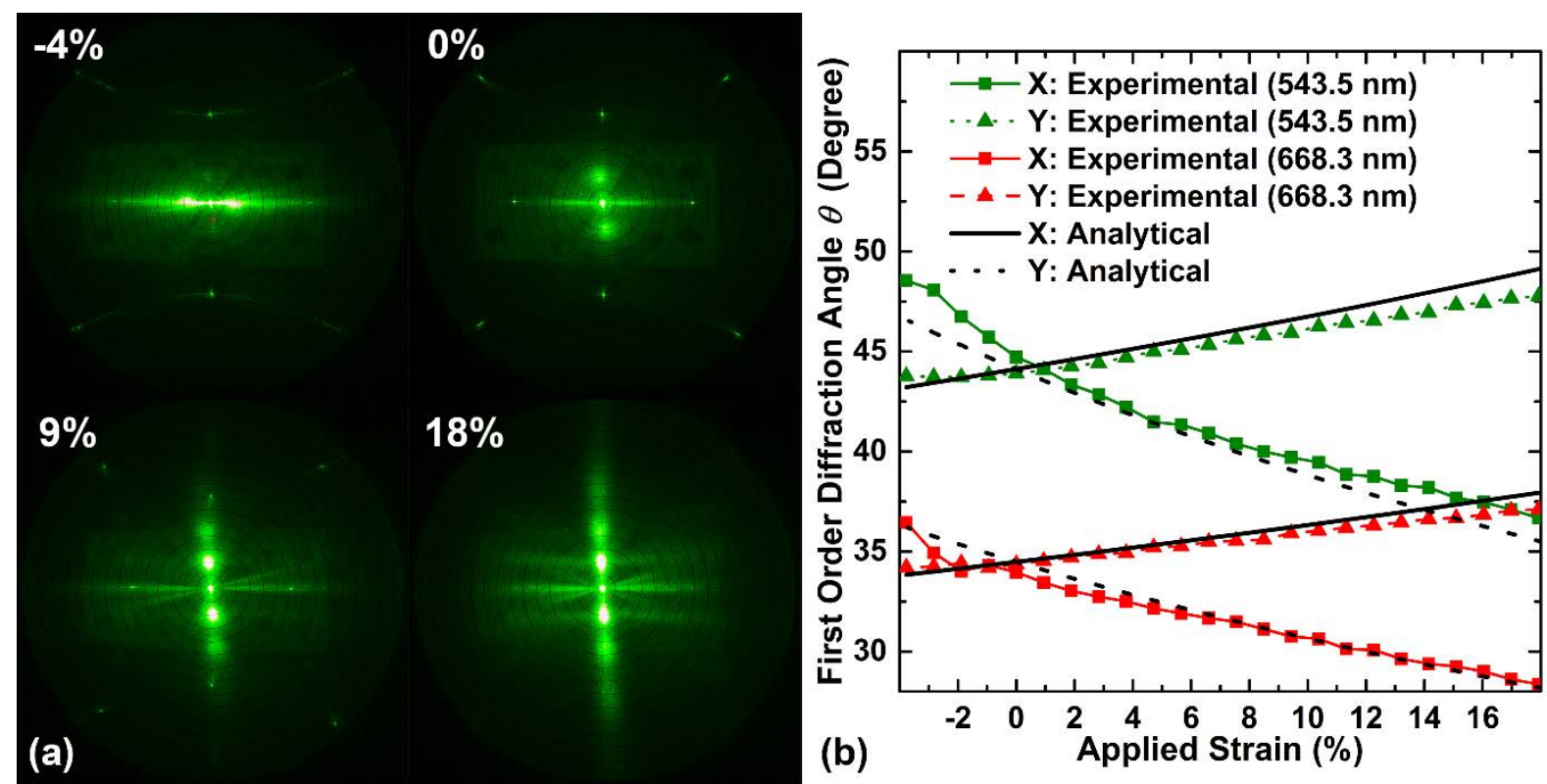

Figure 3. (a) Photographic image obtained at the rear of the semitransparent screen showing the first order diffraction pattern. Displayed are the diffraction pattern of the grating under increasing strain states ranging from $-4 \%$ to $18 \%$. (b) Change in first order diffraction angle $\theta$ under applied mechanical strain. 
(a)

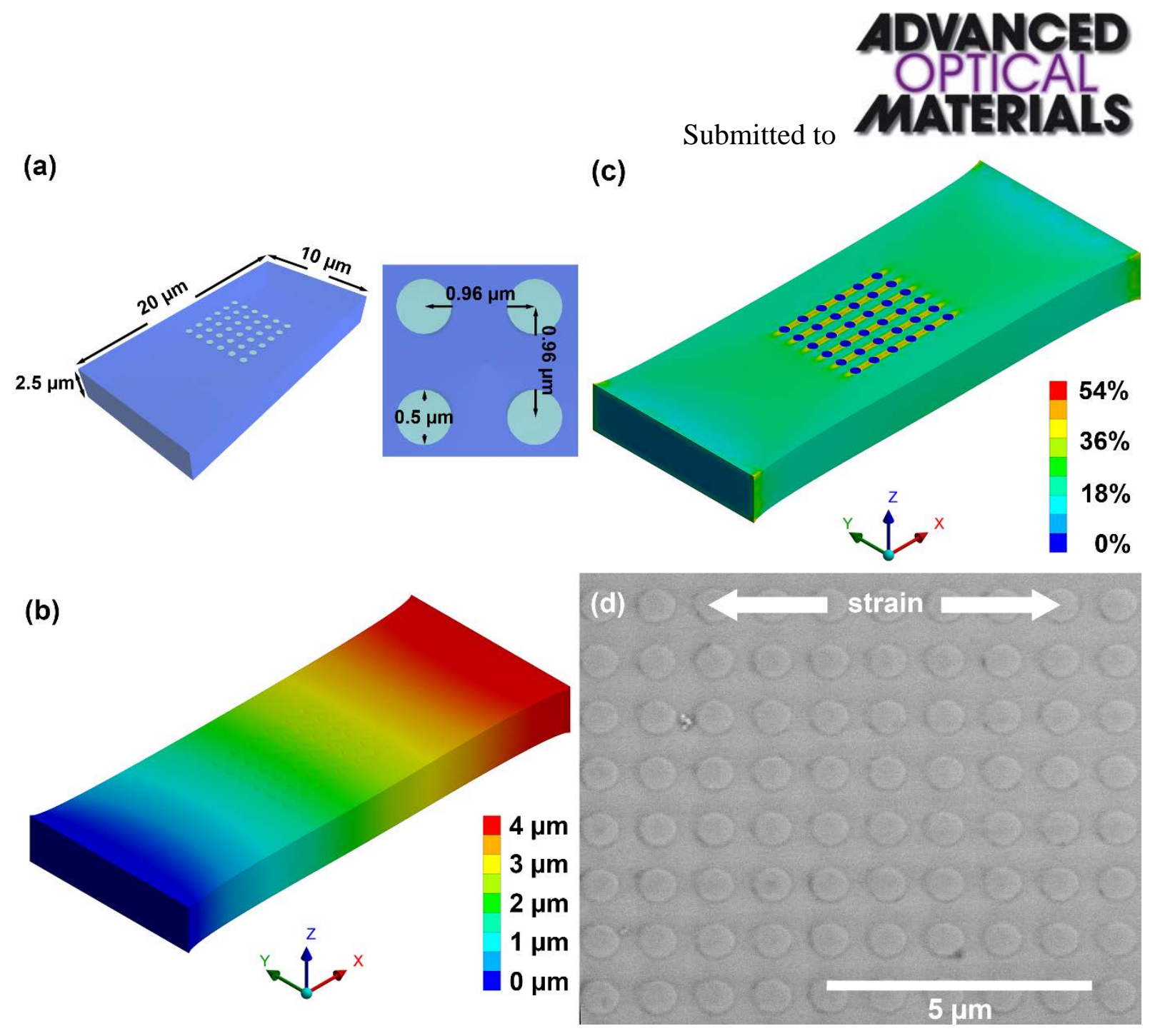

Figure 4. (a) Schematic of the PDMS substrate with the integrated $\mathrm{TiO}_{2}$ dot grating utilized in the finite element modelling analysis. (b) Three-dimensional map of deformation for an applied strain of 20\% (4 $\mu \mathrm{m}$ displacement) in the $\mathrm{X}$ direction for sample clamped at one end. (c) Three-dimensional map of strain distribution (normalized) under condition in (b). (d) SEM image of the gratings obtained in situ under 15\% strain. 
Submitted to
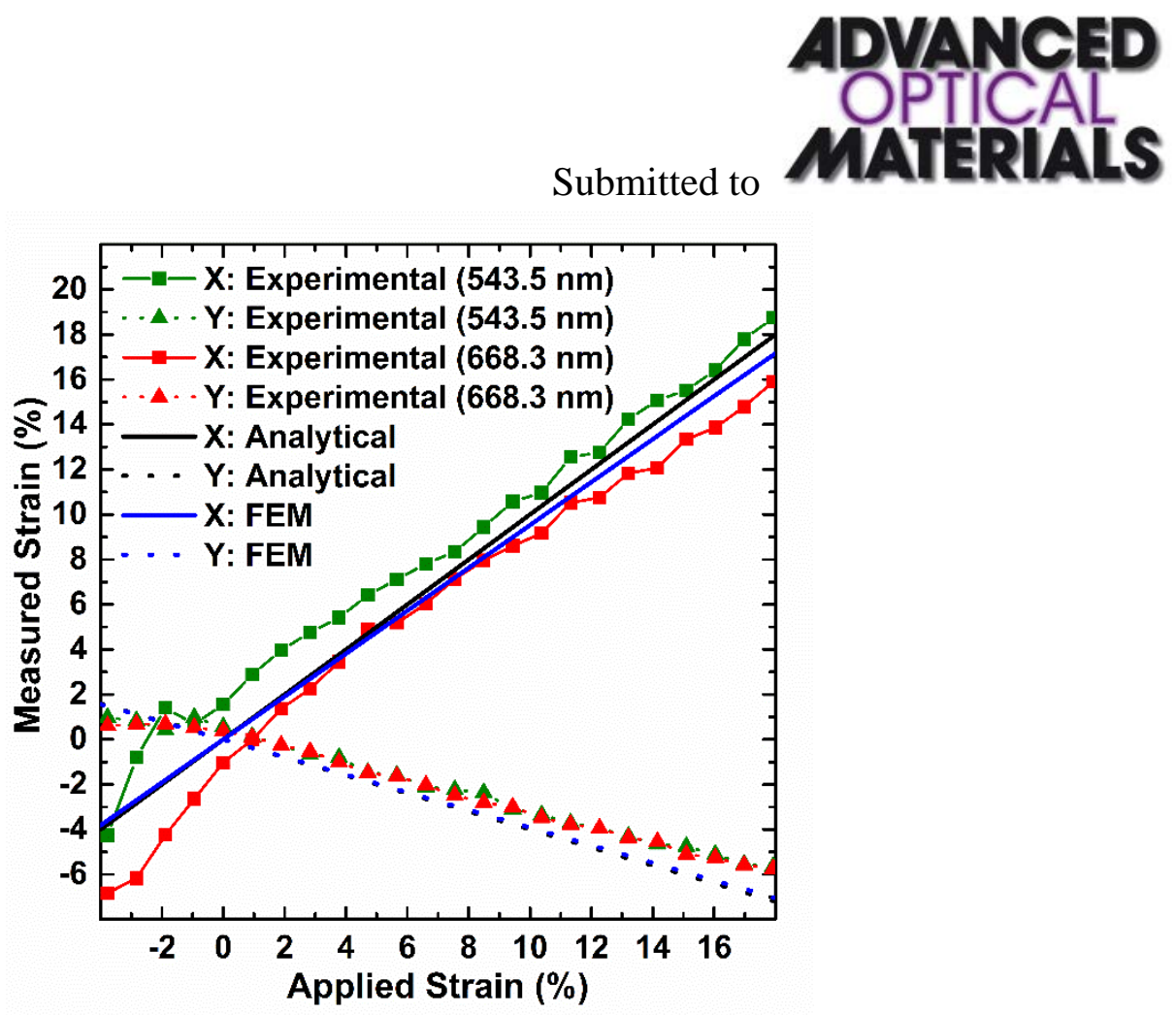

Figure 5. The correlation of applied strain vs. the strain estimated from the diffraction angle. A comparison of the experimental, analytical, and FEM results is presented. 


\section{Table of Contents Entry}

Submitted to

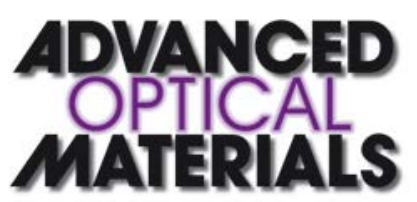

A mechanically tunable grating is demonstrated by introducing high refractive index titanium dioxide $\left(\mathrm{TiO}_{2}\right)$ nanoscale dot gratings into soft, elastomeric polydimethylsiloxane (PDMS). In situ diffraction angle measurements of uniaxial strain-induced grating response are backed by finite element modelling of strain distribution. These gratings offer the distinct advantage of low mechanical impact on the elastomeric substrate as well as excellent linear tunability.

\section{Keywords}

tunable optics, flexible devices, transmission grating, nanolithography, $\mathrm{TiO}_{2}, \mathrm{PDMS}$

\section{Authors}

P Gutruf,* E Zeller, S Walia, S Sriram, and M Bhaskaran*

\section{Title}

Mechanically Tunable High Refractive Index Contrast $\mathrm{TiO}_{2}-\mathrm{PDMS}$ Gratings

\section{ToC Figure}
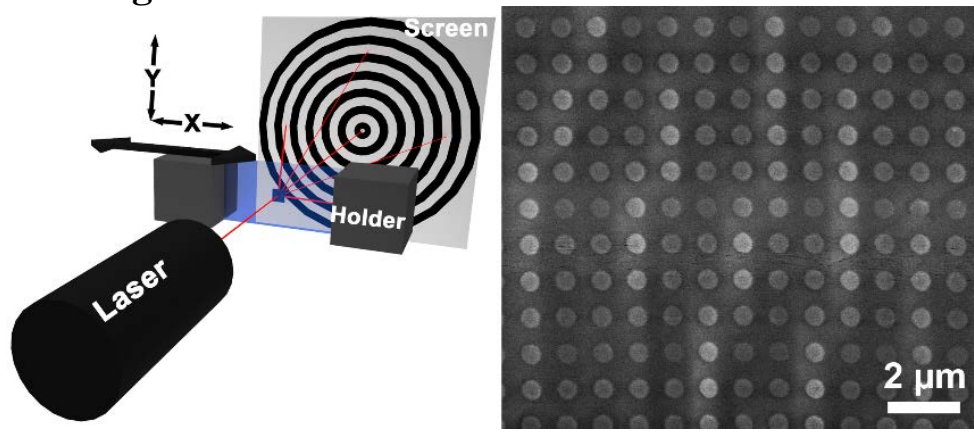